\title{
Коллокации - теория и лексикографическая практика (о концепции П. Дюрчо)
}

\author{
В. М. МОКИЕНКО \\ Кафедра славянской филологии, Санкт-Петербургский государственный университет, \\ Университетская наб., д. 11, RU-199034 Санкт-Петербург \\ E-mail: mokienko40@mail.ru
}

(Received: 16 September 2016; accepted: 31 October 2016)

\begin{abstract}
The presented Dictionary of Collocations is the first of its kind in Slovakia. It covers collocational profiles with nouns and is based on a lexical database of collocations in the Slovak language. The Slovak National Corpus of the Ludovít Stúr Institute of Linguistics at the Slovak Academy of Sciences was used to conduct the research. The database covers collocational profiles of several hundred words of different parts of speech (nouns in the first phase of the project). The Dictionary is aimed at the registration and description of not only multiword lexemes, but also at the registration of the so-called typical collocations having a wide collocability. They are differentiated by frequency, and their number is limited in that way. An innovative approach has been applied for sorting out collocations in the Dictionary. The combinatory of flexional potentials of these elements are the basis for the creation of the so-called collocational templates which serve as the basis for the patterns of collocations.
\end{abstract}

Keywords: Slovak language, collocations, lexicography, collocational profiles, frequency

Проблема коллокаций в лингвистическом освещении прямо связана с теорией и практикой современной фразеологии, которая, как известно, начинается со стилистической типологии устойчивых сочетаний Шарля Балли (см. BALLy 1909, БАлли 1961) и ее творческой актуализации в трудах В. В. Виноградова (см. ВиНоГРАдов 1946, ВиНОГРАДов 1947, ВИНОГРАДов 1977). Фразеологи-лингвисты по-разному стремились и стремятся измерить степень устойчивости и «коллокативности» словосочетаний разного типа, и диапазон таких измерений почти неограничен - от широкого понимания фразеологических единиц признающих любое словосочетание таковыми (см. РойзЕНЗОН 1973, РОЙЗЕНЗОН 1977, КОПЫЛЕНКО 1973, КОПЫЛЕНКО-ПОПОВА 1972, КОПЫЛЕНКО-ПОПOBA 1978, С̆ЕRMÁK 1982, С̆ЕRMÁK 2010 и др.) до узкого, идиоматического их определения (см. В. В. Виноградов, Б. А. Ларин, Р. Эккерт, Н. Ф. Алефиренко, А. В. Жуков, В. М. Мокиенко и др.).

В современной лингвистике проблема коллокаций обрела сейчас новое терминологическое обличие: в славянской фразеологии вместо всем понятных отечественных терминов сочетание, сочетаемость, slovné spojenie и др. исследователи (в том числе и автор обсуждаемой нами концепции П. Дюрчо) предпочитают англоязычное наименование - collocation. Суть явления от этого в принципе не меняется, хотя определенные основания для «смены 
терминологических вех» все-таки есть. Ведь теория и практика сочетаемости /коллокаций получила второе дыхание благодаря новым компьютерным возможностям, связанным с созданием национальных корпусов. И в концепции, и в трудах словацкого исследователя П. Дюрчо анализ проблемы коллокаций делается именно в этом современном ракурсе, с постоянным прицелом в сторону корпусной лексикографии. Опираясь на продуктивный опыт словацкой фразеологии (см. MLACEK 2003, KAČALA 1997, KRALČÁK 2003, DolNíK 1997, OloŠTIAK-IVANOVÁ 2013), лексиколоГии (см. JAROŠOVÁ 2000, OloŠTiAK 2012), лексикографии (см. JAROŠOVÁ 1999, JAROŠOVÁ 2000, RIPKA 1987), синтаксиса (см. KAČALA 2002) и корпусной лингвистики (см. JAROŠOVÁ 1999, IVANOVÁ 2013), а также будучи во многом последователем чешской фразеологии (особенно в духе теоретических и лексикографических трудов Фр. Чермака), П. Дюрчо как германист работает в тесном контакте с известными немецкими исследователями в этой области (например, А. Хэкки Бухофер, Х. Бургер, Т. Рот). При этом его собственная концепция коллокаций имеет самостоятельную теоретическую подоплеку и целеустремленную практическую (т. е. лексикографическую) направленность.

И П. Дюрчо не только убедительно обосновывает свои теоретические постулаты в многочисленных публикациях (ср. ĎuRČo 2008, ĎuRČo et al. 2009: 37, Dúčo 2015a, ĎuRČo 2015b и др.). Любая теория остается абстракцией, не будучи подтвержденной практикой. П. Дюрчо может подтвердить свои теоретические постулаты самым главным практическим критерием - словарной продукцией. Созданный им и его рабочей группой «Словарь словосочетаний. Имена существительные» (ĎURČO-MAJCHRÁKOVÁ 2015) - весомый вклад словацких лингвистов в европейскую коллокационную лексикографию. «Сочетаемость слова нужно понимать, исследовать и регистрировать как явление, имеющее характер континуума от устойчивых оборотов через обиходные/типичные/частотные выражения до неустойчивых сочетаний, реализованных чаще всего в виде актуальных сочетаний слова в новом и неожиданном контексте, - пишет П. Дюрчо в предисловии к своему Словарю. С точки зрения языковой вариантности речь при этом всегда идет не о четко ограниченных ассоциациях, а о сливающейся, перекрывающейся массе единиц - от различных количественных (частотных) и качественных (смысловых) предпочтений до случаев однозначно семантической дифференциации» (ĎurČO-MAJCHRÁKOVÁ 2015: 6).

Сложности составления коллокационных словарей (т. е. словарей сочетаемости) известны. Ведь коллокации - это освоенные в разной степени речевым узусом и литературным употреблением словосочетания. Или, - по формулировке самого словацкого исследователя, - «словосочетания (в лингвистике именуемые также и как коллокации) с психологической точки зрения являются словесными ассоциациями, которые говорящий спонтанно усваивает вместе с усвоением языка» (ĎURČO-MAJCHRÁKOVÁ 2015: 5). И если раньше, в докомпьютерную эру, устойчивость такого рода словосочетаний выверялась «на глазок», с ориентацией на апробированную литературным и 
публицистическим употреблением группу устойчивых словосочетаний, то современные национальные корпусы и выход в интернет-пространство позволяет практически каждое словосочетание признавать более или менее устойчивым, узуальным или хотя бы узуализированным. Отсюда - структурная и семантическая гетерогенность коллокаций, попадающих в корпусы. Для концепции П. Дюрчо исходным пунктом оценки «узуализации» словацких коллокаций в Словаре являются статистически вычисляемые словосочетания.

Имплицитно же коллокативность / неколлокативность в работах П. Дюрчо во многом определяется сопоставлением словацкого материала с материалом других языков - особенно немецкого и русского, с опорой на соответствующие национальные корпуса, что им продемонстрировано на примере анализа словацких коллокаций-субстантивов, характеризующих эмоции. Сопоставив их с коллокациями других языков (ĎUŘ̌o 2016), исследователь попытался ответить на несколько вопросов:

1) Мотивируется ли лексическая устойчивость отдельных коллокаций внутри одного языка либо она имеет межъязыковую, более широкую масштабность и регулярность?

2) Если в сравниваемых языках имеются сопоставимые коллокации, то какова их природа в других языках, где кроются параллели и различия (т. е. предпочтения) в комбинаторике таких субстантивных словосочетаний?

3) Можно ли приписать сопоставимым «коллокатам» в других языках эквивалентные значения и функции, либо они отличаются на основе различных контекстных модусов?

Может показаться, что такое имплицитное «равнение» на межъязыковую коллокационность прямо не связано с задачами составления одноязычного словаря коллокаций. Однако, как показывает материал Словаря, именно имплицитное представление о некоем интерлингвальном коллокационном фоне помогает более толерантно относиться к статистическим критериям отбора материала и в одноязычном словаре коллокаций. Ведь и феномен эквивалентности может быть зависим от дистрибутивных и дифференцирующих прагматических факторов.

Коллокационная лексикография по концепции П. Дюрчо основывается на ряде принципов интерпретации лексической комбинаторики. Исходя из семиотического характера компонентов коллокаций, исследователь разграничивает несколько их типов. Во-первых, это так называемые «иконические фразы», которые можно назвать «композиционными» (kompozičné) или «импликативными» (implikačné) словесными комбинациями (например, blond vlasy, kôñ erdži, potok zurči). Следующий ряд коллокаций - «индексальные» (indexálne), соответственно «симптоматические» (symptomatické), которые автор разграничивает на «конъюнкционные» (konjunkčné) или «ассоциативные» комбинации (например, krvavý zločin, krvavé zore, krvavá ruža, spáchat' zločin, načapovat' pivo, dôrazne žiadat'), а также «глагольно-номинативные словосочетания» (типа dostat' chorobu/mladé/rozum/strach / do nešt'astia niekoho / 
do funkcie niekoho) и «конвенциональные» (konvenčné) или узуальные (например, dat' si sprchu, umyt' si zuby, tuhý fajčiar, čerstvé mlieko, odročit' pojednávanie, čistit' si topánky, leštit' nábytok, šúrovat' chodbu, drhnút' byt, pulirovat' nábytok).

Символические словосочетания являются, с точки зрения знакового характера компонентов, «дисъюнктными» (disjunkčné) либо «иррегулярными» комбинациями (например, navarit' niekomu krvavej polievky, dostat' krvavú po$l i e v k u$ ). Коллокационный профиль слов с количественной точки зрения всегда кажется частотным континуумом коллокаций вокруг базового слова. Фразы, развиваясь в направлении к стабилизации и лексикализации, обретают некоторые новые функции и теряют некоторые свойства в результате отделения и утраты определенных словоформ в новой комбинации. Тем самым происходят изменения в их формальных, синтагматических и парадигматических характеристиках, что отражается на утрате их стандартных парадигматических элементов. Степень этих изменений можно наблюдать на всех уровнях языка.

П. Дюрчо предлагает идентифицировать их с помощью тестов, включающих понятие так называемого «6С-метода»:

1) «Коокурентный тест» (kookurenčný test). Он исходит из статистического установления так называемых «биграммов» и «n-граммов» и служит исходной эмпирической базой дальнейшего анализа. Коллокационная грамматика при этом позволяет идентифицировать сигнификативное отношение между словами - например, starý $(x)$ a problém $(y)$ в конструкции $x$ bez $y$ :

2) «Коллокационный тест» (kolokačný test) предназначен для разграничения случайных частотных «коокуренций» (kookurence) от реальных синтагматических конструкций, обозначаемых иногда как «колигации» (koligácie). Речь идет об операции, при которой анализируются дегенерированные коокуренции с точки зрения их синтагматической «целостности» (integrita).

3) «Категориальный тест» (kategoriálny test) определяет, сохранили ли компоненты словосочетания полную свободу форм, либо они частично или полностью ограничены, например, при словосочетании starý otec идентифицируется как формообразующая (*stari, najstarši otec), так и деривационная блокада (*prestarnutý otec).

4) «Коммутационный тест» (komutačný test) устанавливает свободу/устойчивость словосочетания путем тестирования заменяемости компонентов в рамках семантических парадигм. В случае сочетания лексем идентифицируется, например, блокада семантической парадигмы идентичность /синонимия (starý otec - *otec v rokoch) и оппозиционность/антонимия (starý otec *mladý otec).

5) «Конструктивный тест» (konštrukčnýtest) проверяет возможности синтаксической трансформации словосочетания. С помощью конструктивных, композиционных, исключающих и др. тестов можно, по концепции П. Дюрчо, проверить целостность синтагмы, ее особый статус в оппозиции «свободная - устойчивая синтагма», например, starý otec - *Otec, ktorý je starý; 
*Aký je otec? *Je starý; *otcova staroba; *starý a chorý otec; *Čo sa deje s otcom? *Otec starne; Je to môj starý otec - *Je to môj... otec и т. д.).

6) «Композиционный тест» (kompozičný test) проверяет возможность семантической членимости и самостоятельности компонентов по отношению к целостному значению словосочетания (например, starý otec $\neq \Sigma$ 'мужчина в отношении к своему ребенку, имеющий много лет, преклонный возраст', но $=\Sigma$ 'отец матери или отца').

При рассмотрении «коллокабельности» (т. е. сочетаемости) слов для нужды «коллокационной лексикографии» (т. е. словарей сочетаемости) П. Дюрчо и его соавторы полагают, что глобальный профиль коллокации слов связан с двумя категориями отношений: 1) с общими категориальными особенностями слов; 2) с парадигматическими формами слова.

Именно в них и через них, по мысли П. Дюрчо, путем постепенного отделения и освобождения отдельных компонентов словосочетания и проявляется «коллокационный» (т. е. сочетаемостный) потенциал, смысловая структура слова и узуальная или устойчивая «коллокабельность» (т. е. сочетаемость).

Составители изданного словаря при извлечении коллокационного профиля слова из корпусов исходили первоначально из их частотного распределения и степени сигнификативности соответствующей коокуренции (т. е. связанности). С помощью унарных, бинарных/симметрических или тринарных правил «скетч-грамматики» (т. е. коллокационной грамматики), которую можно эффективно использовать, кроме прочего, и в так называемых «сопоставительных корпусах» (comparable corpora) при сопоставительном исследовании путем так называемых «компатибильных коллокационных грамматик», П. Дюрчо и его соавторы идентифицируют исходную синтагматику слов. При этом используются статистические методы.

Главным этапом исследования глобальной сочетаемости описываемой в словаре лексемы, следовательно, является установление «коокурентного» потенциала (т. е. типа связанности между компонентами словосочетания) слова. На его основе создается коллокационный профиль слова. При его создании П. Дюрчо исходит из пяти принципов.

\section{1. Принцип минимальной целостности}

На уровне текста регистрируются различные полнозначные словосочетания, которые далее членятся на так называемые «минимальные автономные коллокации» (minimálne autonómne kolokácie). Характер лексической коллокабельности таких минимальных коллокаций дифференцируется на два типа: [кон]текстуальное расширение коллокаций, либо узуальное расширение. Здесь возможны и варианты - например, plný úväzok и plný pracovný úväzok. При этом, с точки зрения минимальной целостности, такие сочетания, например, как prvá pomoc и linka prvej pomoci образуют две самостоятельные коллокации. 


\section{2. Принцип формальной целостности}

Здесь П. Дюрчо исходит из факта, что коллокации функционируют в текстах как комбинации словоформ. Если трансформация коллокации в основную словоформу возможна, то такая форма является его коллокационной леммой. В случае же абсолютно неизменяемой, «окаменевшей» коллокации, в которой произошло полное упразднение словоформ компонентов из системы парадигматических отношений, коллокационной леммой является лишь конкретная комбинация компонентов.

Принцип формальной целостности учитывает факт, что коллокации часто «констеллируются» до неизменности на уровне словоформ и не трансформируются до основной, исходной формы. Коллокационной леммой при этом является соответствующий вид словоформы.

Принцип минимальной целостности и принцип формальной целостности могут, согласно концепции П. Дюрчо, быть основой для лексикографического распределения коллокаций в коллокационном словаре. Речь здесь идет о морфематическом принципе. Для многочленных же структур тестируется возможность их «трансформации» в биграмм, поскольку они опираются на основные модели - например, naivný ako malé diet'a = Adj + Sub (= naivné diet'a); čistý ako Kristovo l'avé oko = Adj + Sub (čistý ako oko); vysoký pät' metrov $=\mathrm{Adj}+\mathrm{Sub}(=$ meter vysoký).

\section{3. Принцип синтагматической целостности}

С точки зрения автономности минимальной коллокации П. Дюрчо выделяет три типа их коллокабельности с окружением: 1) коллокации, автономные - с открытой лексической «коллокабельностью» (например, celý: celé číslo $\mid$ celý človek $\mid$ celý deň | celé šaty | celý chlieb | celý [cestovný] lístok; podobný otcovi); 2) связанные с лексически ограниченной коллокабельностью (например, celá kopa [niekoho, niečoho]; rovný nule: výsledok/zlomok/súčin/tok/súčet / determinant/diskriminant); 3) изолированные с лексически ограниченной коллокабельностью (например, Celá matka!|Celý otec!|; väčš́ /menší alebo rovný nule|k podobným výsledkom: dopracovat' sa /dospiet'/dôjst'...|).

\section{4. Принцип синтаксической целостности}

Принцип синтаксической целостности отталкивается от факта, что коллокации имеют разные синтаксические функции - например, атрибутивные (silný a odolný: človek/materiál / konštrukcia) или предикативные (silný a odolný: byt' voči niekomu, niečomu).

Синтаксический принцип важен и с точки зрения регистрации валентности коллокаций. Поэтому он может служить и как еще один классификационный критерий. Валентностный потенциал коллокаций членит их в самостоятельные подтипы, - например, при прилагательном hotový регистрируются коллокации в соответствии с их валентной сочетаемостью: byt hotový: 
celkom h.| čoskoro h. |dávno h.|definitívne $h$. | kompletne $h . \mid$ konečne $h . \mid$ načas $h$. okamžite $h . \mid$ prakticky $h$. psychicky $h$.| rýchlo $h$.| skoro $h$.| spolovice $h$.| úplne $h$. včas $h . \mid$ и др.

Синтаксический принцип отражает и факт, что некоторые прилагательные сочетаются с инфинитивом. И здесь можно зарегистрировать тройственный характер их коллокабельности. При этом их валентностный потенциал широк и специфичен. Например, прилагательное ochotný образует следующие коллокации:

- автономные: byt' o. urobit' niečo;

- связанные: byt'o. urobit' niečo bez problémov/rozpakov/váhania...|byt'o.; urobit' niečo do istej / určitej miery |byt' o. urobit' niečo kvôli niekomu, niečomu| byt'o. urobit' niečo napriek niečomu |byt'o. urobit' niečo za (istých / primeraných / určitých...) podmienok|;

- изолированные: byt' o. urobit' čokol'vek/všetko... (na svete) pre niekoho, pre niečo $\mid$ byt'o urobit' niečo za peniaze |byt'o. urobit' niečo z lásky $k$ niekomu...

\section{5. Принцип семантической целостности}

Очевидно, что на семантическую целостность коллокаций оказывают влияние и формальные, структурные и функциональные особенности конкретного словосочетания. П. Дюрчо определяет возможности семантической «раздельнооформленности» и свободы компонентов посредством композиционного теста. Тем самым очерчивается и ограничивается не только статус «диспозитивности» (dispozitívnosti) словосочетания как кандидата составной части словарного состава, описываемого в Словаре, но и определяется мера семантической трансформации компонентов с точки зрения частичной или полной идиоматичности словосочетания.

Вчитываясь в Словарь П. Дюрчо, каждый славист оценит коллокационный потенциал словацкого языка. Невольно вспоминается крылатая фраза А. С. Пушкина: «Язык неистощим в соединенье слов...». Вот почему, - раз уж обязанности рецензентов предполагают определенные критические замечания, хочется высказать три небольших соображения.

Во-первых, при изложении своей продуктивной концепции, как кажется, П. Дюрчо несколько перенасыщает его терминами-англицизмами. Современный читатель еще более или менее постепенно привыкает к таким словам, как kolokácie (инкорпорированным в словацкий язык в 2004 году) и его производным типа kolokačná lexikografie, kolokát, kolokabilita, kolokačný profil slova, kolokačná lema, но перегруженность терминологических (и не только) замен собственно словацкой лексики заимствованиями, порождающими у читателя нетерминологические ассоциации - например, konjunkčné a konvenčné kombinácie, separácia a emancipácia, integrita, kookurence, kookurenčný test, как представляется, несколько затемняет смысл изложения концепции для читателей-славян.

Второе критическое замечание связано с неразграничением в Словаре разных типов связанности компонентов словосочетания, которая теорети- 
чески, как мы видели, словацким ученым довольно тонко и убедительно обосновывается. В корпусе же Словаря коллокации приводятся в строго алфавитной последовательности, но без дифференциации на - хотя бы по классификации В. В. Виноградова - фразеологические сращения, фразеологические единства и фразеологические сочетания и под. Так, в словарной статье на существительное zem 'земля' полусвободные словосочетания типа bohatá zem, dobrá zem, holá zem, tvrdá zem и т. п. поданы в одном ряду с neznámá zem и zaslubená zem (ĎurČO-MAJCHRÁKOVÁ 2015: 340-341). Поскольку дефиниции и стилистические пометы в словаре отсутствуют, то читатель может недифференцированно воспринять такие словосочетания, хотя первое навевает ассоциации с латинским источником (terra incognita), а второе - ассоциации с библейским текстом и современными публицистическими его употреблениями в качестве наименования Израиля. Собственно, оба эти выражения можно причислить к идиомам или публицистическим перифразам с высокой степенью связанности и устойчивости. Было бы целесообразно, как кажется, такого рода коллокации выделять из общего ряда особым знаком или шрифтом.

При всей полноте избранного с помощью новейших технологических методов материала читатель, даже не искушенный в компьютерной технике, может обнаружить в корпусе Словаря и некоторые лакуны. Так, неясно, почему здесь отсутствует такое слово с высоким «коллокационным профилем» (kolokačný profil), как zlato. Ведь в словацком языке (как и во всех европейских) оно очень активно образует и свободные, и полусвободные, и устойчивые словосочетания - например, čisté zlato, čire zlato, rýdze zlato, červené zlato, zlomkové zlato, mačacie zlato, čierne zlato, biele zlato и т. П. Легко увидеть, что и здесь можно выделить некую долю устойчивых перифрастических оборотов (например, переносно обозначающих уголь или сахарную свеклу), которые близки к идиоматике.

Как показывают основательные и логически продуманные теоретические установки авторов вышедшего словацкого коллокационного словаря (как и другие лексикографические работы П. Дюрчо), составление такого рода словарей - трудоемкая новаторская работа. Она во многом и облегчается, но и усложняется достижениями современной корпусной лингвистики и необъятными возможностями бездонных материальных баз интернета. Как пишет сам концептолог этой работы, - «создание словаря коллокаций - это чрезвычайно интересный лингвистический и лексикографический вызов. Он требует детального анализа материала и использования всех доступных технологий корпусной лингвистики. Трансформация „коллокационного“ [т. е. сочетаемостного] профиля слова в словарную статью, однако, требует еще научных дискуссий, связанных с отбором, типологией и классификацией коллокаций и сообразности их распределения в словаре с точки зрения пользователя» (ĎURčo 2015a: 435). Действительно, дискуссии о различных типах фразеологических словарей в европейской лексикографии необходимы. Ведь в этой области лингвистики остаются еще немалые лакуны: у нас еще очень 
мало надежных этимологических словарей европейской идиоматики и паремиологии, отсутствуют для многих языков (в том числе и словацкого) словари диалектной фразеологии и основательные словари крылатых слов и т. д. Но теперь благодаря трудам П. Дюрчо словацкие читатели получили первый фундаментальный словарь словосочетаний имен существительных. Задуманы автором и подобные словари для имен прилагательных, глаголов, частиц и т. д. Хочется пожелать, чтобы эти перспективные планы словацкого фразеолога и фразеографа были успешно осуществлены.

\section{Литература}

БАлли 1961 = БАлли Шарль: Франиузская стилистика. Москва: «Государственное издательство иностранной литературы», 1961.

ВинОГРАДОВ 1946 = ВиНОГРАДОВ В. В. Основные понятия русской фразеологии как лингвистической дисциплины. В кн.: Труды юбилейной научной сессии Ленинградского государственного университета 1919-1944. Секция филологических наук. Ленинград, 1946. 45-69. [То же см. ВиногРАдов 1977: 118-139.]

ВиНОГРАДОВ 1947 = ВИНОГРАДОВ В. В. Об основных тиПах фразеологических единиц в русском языке. В кн.: А. А. Шахматов (1864-1920). Сборник статей и материалов. Москва-Ленинград, 1947. 339-364. [То же см. ВиногРАдов 1977: 140-161.]

ВИНОГРАДОВ 1977 = ВинОГРАДОВ В. В. Избранные труды. Лексикология и лексикография. Москва: «Наука», 1977.

КОПЫЛЕнко 1973 = КОПЫЛЕнко М. М. Сочетаемость лексем в русском языке. Москва: «Просвещение», 1973.

КОПЫЛЕНКО-ПОПОВА 1972 = КОПЫЛЕНКО М. М., ПоПОВА З. Д. Очерки по общеей фразеологии. Воронеж: «Издательство Воронежского университета», 1972.

КоПЫЛЕНКО-ПоПОВА 1978 = КоПЫЛЕНКо М. М., ПоПОВА З. Д. Очерки по общей фразеологии. Воронеж: «Издательство Воронежского университета», 1978.

РойзЕнЗОН 1973 = РойзЕНЗОН Л. И. Лекции по общей и русской фразеологии. Самарканд: «Издательство СамГУ», 1973.

РойзЕнЗОН 1977 = РойзЕнЗОН Л. И. Русская фразеология. Самарканд: «Издательство СамГУ», 1977.

BAlly 1909 = BALly Charles: Traité de stylistique française. Paris: Librairie Klincksieck, 1909.

ČERMÁK 1982 = ČERMÁK František: Idiomatika a frazeologie češtiny. Praha: Univerzita Karlova, 1982.

ČERMÁK 2010 = ČERMÁK František: Lexikon a sémantika. Praha: Lidové noviny, 2010.

Dolník 1997 = Dolník Juraj: Jazykové princípy vo výstavbe frazém. In: ĎuRČo P. (red.) Frazeologické štúdie 2. Bratislava: Esprima, 1997. 36-44.

ĎuRČO 2008 = ĎuRČo Peter: Zum Konzept eines zweisprachigen Kollokationswörterbuchs. Prinzipien der Erstellung am Beispiel Deutsch $\leftrightarrow$ Slowakisch. In: HausmanN Franz J. (Hrsg.) Collocations in European Lexicography and Dictionary Research. (Lexicographica 24.) Tübingen: Max Niemeyer, 2008. 69-89.

ĎuRČo 2015a = ĎuRČo Peter: K princípom kolokačnej lexikografie. Extrakcia a spracovanie kolokácií s adjektívami. In: Prirodzený vývin jazyka a jazykové kontakty. (Jazykovedné štúdie 32.) Bratislava: Veda, 2015. 426-437. 
ĎurČO 2015b = ĎurČo Peter: Gebrauch der Kollokationen und Probleme der zweisprachigen Kollokationslexikographie für Lerner. In: Schmidlin R., BeHrens H., Bickel H. (Hrsg.): Sprachgebrauch und Sprachbewusstsein. Implikationen für die Sprachtheorie. Berlin-Boston: Walter de Gruyter, 2015. 221-237.

ĎuRČO 2016 = ĎuRČo Peter: Kollokative Relationen der emotionalen Substantive im Deutschen, Slowakischen, Russischen sowie anderen Sprachen. In: Slavofraz 2016. Internationale Konferenz „Phraseologie und (naive) Psychologie“. 7.-10. April 2016. Graz, 2016. 15-16.

ĎurČo et al. 2009 = ĎurČo Peter, GARABík Radovan, MAJChrÁKOvÁ Daniela, ĎurČo Matej: Dictionary of Slovak Collocations. In: KoseskA-Toszewa V., Dimitrova L., Roszko R. (ed.) Representing Semantics in Digital Lexicography. Innovative Solutions for Lexical Entry Content in Slavic Lexicography. Mondilex Fourth Open Workshop. Warsaw, 29 June - 1 July 2009. Warsaw: Institute of Slavic Studies, Polish Academy of Sciences, 2009. 128-137.

ĎurČO-MAJChrÁKOVÁ 2015 = ĎurČo Peter, MAJCHRÁKOvÁ Daniela: Slovník slovných spojení. Podstatné mená. Trnava: Univerzita sv. Cyrila a Metoda, 2015.

IVANOVÁ 2013 = IVANOVÁ Martina: Kolokácie v korpuse, viacslovné pomenovania v slovníku. Úvodné poznámky k príprave slovníka viacslovných pomenovaní. In: IMRICHOVÁ M., KESSELOVÁ J. (red.) Jazyk je zázračný organizmus... Metamorfózy jazyka a jazykovedy. Zbornik príspevkov venovaných prof. PhDr. Ivorovi Ripkovi, DrSc., emer. prof. PU, pri príležitosti jeho životného jubilea. Prešov: Filozofická fakulta Prešovskej univerzity v Prešove, 2013. 132-147.

JAROŠOVÁ 1999 = JAROŠOVÁ Alexandra: Problém vyčleňovania ustálených lexikalizovaných spojení pomocou štatistických nástrojov. Jazykovedný časopis 50 (1999): 94-100.

JAROŠOVÁ 2000 = JAROŠOVÁ Alexandra: Viacslovný termín a lexikalizované spojenie. In: BuZÁssyová K. (red.) Človek a jeho jazyk 1. Jazyk ako fenomén kultúry. Na počest' profesora Jána Horeckého. Bratislava: Veda, 2000. 481-493.

KAČALA 1997 = KAČALA Ján: Lexikalizované spojenia a frazeologické jednotky. In: ĎuRČo P. (red.) Frazeologické štúdie 2. Bratislava: Komisia pre výskum frazeológie pre Slovenskom komitéte slavistov, 1997. 95-102.

KAČALA 2002 = KAČALA Ján: Syntax lexikalizovaných spojení. Studia Academica Slovaca 31 (2002): 100-110.

KRALČÁK 2003 = KRALČÁK L'ubomír: K otázke hraníc medzi frazémami a analytickými verbo-nominálnymi spojeniami. In: MLACEK J., ĎurČo P. (red.) Frazeologické štúdie 3. K 13. kongresu slavistov v Lubl'ane. Bratislava: Stimul, 2003. 116-123.

MLACEK 2003 = MlaceK Jozef: Obraznost' slovenskej frazeológie. In: Dolník J., MLACEK J., ŽIGO P. Principy jazyka. Bratislava: Stimul, 2003. 49-82.

OLOŠTIAK 2012 = OLOŠTIAK Martin: K problematike delimitácie viacslovných pomenovaní a vol'ných syntaktických konštrukcií. In: BuzÁssyová K., CHOCHOLOVÁ B., JANOČKOVÁ N. (red.) Slovo v slovníku. Aspekty lexikálnej sémantiky - gramatika-štylistika (pragmatika). Bratislava: Veda, 2012. 126-139.

OloštiaK-IVANOvÁ 2013 = OloŠTiAK Martin, Ivanová Martina: Kapitoly z lexikológie. Lexikálna syntagmatika a viacslovné pomenovania. Prešov: Filozofická fakulta Prešovskej univerzity v Prešove, 2013.

RIPKA 1987 = RIPKA Ivor: Viacslovné spojenia a ich lexikografické spracovanie. In: RIPKA Ivor (red.): Jazykovedné štúdie 21. Dialektológia. Bratislava: Veda, 1987. 7-20. 